\title{
Geriatric Sleep Medicine, a Young Field
}

\author{
Lionel Soyeux \\ Geriatric Sleep and Memory Clinics, Hopital de Lunéville, Lunéville, France
}

Geriatric Sleep Medicine, also known as sleep medicine of old age, is medical field dealing with the prevention, diagnosis and treatment of sleep disorders in older adults.

From the 2000s, through the pioneering approach of the two physicians, Dr. S. Hakki Onen (University of Lyon, France) and Dr. Fannie Onen (University of Paris, France), Geriatric Sleep Medicine was structured as a new clinical sub-specialty.

These visionaries opened first Geriatric Sleep Medicine Centers dedicated to the prevention, diagnosis and treatment of sleep disorders of older patients with medical comorbid conditions and disabilities. For about two decades these centers encompass patient care, research, and educational missions.

In 2006, the French Ministry of Health released a report on sleep including a Geriatric Sleep Medicine section co-authored by Onen $\mathrm{F}$ and Onen SH [1]. It was highlighted that sleep disorders in older people are usually unrecognized and/or untreated, contributing to a wide range of deleterious health and safety consequences including sedative drug abuse, cognitive impairment, cardiovascular complications, post-operative hazards, falls/fractures and increased mortality. Consequently, authors called for increased awareness among healthcare professionals about the physiology of healthy sleep and sleep disorders in older adults and the development and implementation of education programs to promote the early diagnosis and appropriate treatment of sleep disorders. The SFRMS (French Sleep Society) supported this call by organizing special sessions on sleep disorders and aging during its annual meetings.

Later, in 2009 the first and unique Geriatric Sleep Medicine School was created in both Universities Paris and Lyon deliver-

Received: August 11, 2019 Revised: September 6, 2019

Accepted: September 10, 2019

Corresponding author: Lionel Soyeux, MD, Geriatric Sleep and Memory Clinics, Hopital de Lunéville, 6 rue Jean Girardet, 54300 Lunéville, France.

Tel: 33-83-74-50-24, Fax: 33-6-16-07-09-73, E-mail: lionel.soyeux@laposte.net

(a) This is an Open Access article distributed under the terms of the Creative Commons Attribution Non-Commercial License (https://creativecommons.org/ licenses/by-nc/4.0) which permits unrestricted non-commercial use, distribution, and reproduction in any medium, provided the original work is properly cited. ing a post graduate certificate (DIU de Médecine du Sommeil et Vieillissement) [2]. This one year education program includes both theoretical courses and bedside teaching.

In addition, since 2010, the Aging and Sleep International Meeting is the premier educational event in Geriatric Sleep Medicine, providing the latest information on clinical care and research [3].

In a global perspective, all previous initiatives are necessary but insufficient to promote adequate care to older adults. Every country in the world is experiencing growth in the number and proportion of older persons in their population. According to the United.

Nations, the number of people in the world aged 60 or over is projected to double by the mid-century (from 901 million in 2015 to nearly 2.1 billion in 2050). As the population ages globally with multiple chronic diseases and increasing sleep disorders, Geriatric Sleep Medicine is becoming more needed.

For the coming decades this young field will face some challenges. First, basic research efforts focused on aging, chronobiology, neurodegenerative diseases and sleep are needed.

Despite scientific breakthroughs during the past decades that have expanded our knowledge on the cellular and molecular bases of circadian rhythms, sleep and aging, therapies that effectively improve sleep and health, chronic insomnia and neurodegenerative disease related REM behavior disorders are still lacking [1]. Second, sleep assessment questionnaires tailored to and validated in older populations are central for the routine clinical works as well designed large epidemiological studies. In the past decades, the use of invalid tools such as Epwoth Sleepiness Scale in older populations with multimorbidity induced false conclusions (e.g. absence of excessive daytime sleepiness in older sleep apnea populations) [4]. Rapid and reliable instruments to assess sleepiness [4] or screen for sleep apnea have become essential for a large diffusion in older populations [5]. Third, create an international research network that connects individual investigators, research programs, and research centers. Aging and Sleep International Meeting [3] will continue to facilitate these international connections. Undoubtedly, research and clinical progress will help attain 
a desirable quality of life with aging and a reduced morbidity.

\section{Conflicts of Interest}

The author has no potential conflicts of interest to disclose.

\section{ORCID iD}

Lionel Soyeux (D)

https://orcid.org/0000-0002-5413-8369

\section{REFERENCES}

1. Health and solidarity ministry. Report on sleeping. Available at: https://solidarites-sante.gouv.fr/IMG/pdf/rapport-5.pdf. Accessed June 19, 2019.
2. Paris-Descartes University / Lyon 1-University. Health medicine in geriatry post graduate certificate. Available at: http://www.sfrms-sommeil.org/wpcontent/uploads/2012/11/DIU-Som-GerontoProgrammeG\%C3\%A9n\%C3\%A9ral.pdf. Accessed June 19, 2019.

3. International Association of Sleep Research in Gerontology. Aging and Sleep June 29-30, 2017 International Meeting. Available at: http://www.aging-sleep.com/en/pages/aging-and-sleep-2017-welcome. Accessed June 19, 2019.

4. Pak VM, Onen SH, Gooneratne NS, Falissard B, Onen F. Observation and interview-based Diurnal Sleepiness Inventory for measurement of sleepiness in older adults. Nat Sci Sleep 2017;9:241-247.

5. Onen SH, Dubray C, Decullier E, Moreau T, Chapuis F, Onen F. Observation-based Nocturnal Sleep Inventory: screening tool for sleep apnea in elderly people. J Am Geriatr Soc 2008;56:1920-1925. 